\title{
EDITORIAL
}

Sheila Vieira de Camargo Grillo*

Universidade de São Paulo, São Paulo, SP, Brasil

Ana Lúcia Guedes-Pinto**

Universidade Estadual de Campinas, Campinas, SP, Brasil

Maria Inês Batista Campos*****

Universidade de São Paulo, São Paulo, SP, Brasil

\section{O AUTOR E O SER HUMANO POR TRÁS DE PROBLEMAS DA CRIAÇÃO DE DOSTOIÉVSKI (1929)}

A obra de Mikhail Bakhtin ficou conhecida do público brasileiro principalmente por meio das traduções disponibilizadas a partir do final dos anos 1970. Sua primeira obra publicada na União Soviética em 1929, Problemas da criação de Dostoiérski, foi tema do Colóquio Internacional "90 anos de Problemas da obra1 de Dostoiérski (1929-2019)”. É inédita no Brasil, mas tem previsão de publicação para o início de 2021 pela Editora 34. É apenas em 1993 que é divulgada a primeira

* Professora doutora da Faculdade de Filosofia, Letras e Ciências Humanas da Universidade de São Paulo - USP, São Paulo, SP, Brasil; https://orcid.org/0000-0003-0480-2660; sheilagrillo@ vol.com.br

** Professora doutora da Faculdade de Educação da Universidade Estadual de Campinas - Unicamp, Campinas, SP, Brasil; https://orcid.org/0000-0002-0857-8187; alguedes@mpc.com.br

**** Professora doutora da Faculdade de Filosofia, Letras e Ciências Humanas da Universidade de São Paulo - USP, São Paulo, SP, Brasil; https://orcid.org/0000-0003-0480-2660; maricamp@usp.br

1 A diferença nos títulos - criação e obra - deve-se ao fato de que, à época do Colóquio, Ekaterian Vólkova e Sheila Grillo estavam trabalhando na tradução com título provisório Problemas da obra de Dostoiévski. Durante as discussões do evento, as tradutoras entenderam que o termo russo "tvórtchestvo" ficaria melhor traduzido como "criação". Gratidão a Ekaterina Vólkova Américo (UFF) por ter revisado e corrigido os acentos de nomes próprios russos. 
Linha D'Água (Online), São Paulo, v. 33, n. 3, p. 1-23, set.-dez. 2020

biografia de Mikhail Bakhtin na Rússia, Mikhail Bakbtin:páginas da vida e da obra, e recentemente, em 2017, surge uma segunda biografia na conhecida e tradicional coleção russa "A vida de pessoas extraordinárias"2. Uma possível e provável explicação para esse lapso temporal foi o fim da União Soviética em 1991 no processo conhecido como perestróika (literalmente, reconstrução), pois, como se sabe, Bakhtin foi perseguido, condenado e exilado no Cazaquistão pelo regime soviético. A fim de melhor compreendermos as relações entre vida e obra, nosso objetivo com este ensaio introdutório é, primeiramente, trazer informações sobre a vida e a obra de Mikhail Bakhtin e, em segundo lugar, apresentar os artigos deste número33.

\section{Михаил Бахтин: страницы жизни и творчетва (1993) [Mikhail Bakhtin: páginas da vida e da obra]}

Primeira biografia de Mikhail Mikháilovitch Bakhtin em formato de livro na Rússia, esta obra foi lançada em 1993 e escrita por Semen Kónkin, teórico da literatura e professor entre 1976 e 1993, no mesmo departamento que Bakhtin chefiou em Saránsk, e por sua filha, Larissa Kónkina, também teórica da literatura. Nas duas breves páginas de apresentação, os autores ${ }^{4}$ reconhecem que a primeira biografia de M. M. Bakhtin foi publicada nos Estados Unidos e anunciam o objetivo de escrever uma pequena biografia na qual sua obra é abordada como parte de sua vida, pois a análise do processo de formação da sua produção teórica estava em curso na Rússia por outros pesquisadores. Aqui provavelmente os autores se referem à organização das M. M. Bakhtin. Obras reunidas por Serguei Botcharóv, cujo primeiro volume saiu em 1997. As fontes da biografia são, primeiramente, a própria

2 Há um capítulo de livro sobre essa biografia: GRILLO, S. V. C. O retrato de Mikhail Bakhtin em sua mais recente biografia russa (2017). In: BRAIT, B.; PISTORI, M.H.C.; FRANCELINO, P.F. Linguagem e conhecimento (Bakhtin, Volóchinov, Medviédev). Campinas: Pontes, 2019. p. 15-43.

3 A escrita de biografias sobre cientistas não é muito comum no Brasil, mas a Rússia tem uma longa tradição, iniciada no século XIX e que permanece até os dias atuais.

4 A biografia de Kónkin e Kónkina apresenta um estilo bastante sóbrio e repleto de notas com as fontes das informações, bem como um tom respeitoso em relação ao biografado. Aqui descobrimos dados fundamentais não só sobre Bakhtin-autor de Problemas da criação de Dostoiévski, mas também sobre Bakhtin-ser humano e seu tempo. 
Linha D'Água (Online), São Paulo, v. 33, n. 3, p. 1-23, set.-dez. 2020

convivência dos autores com M. M. Bakhtin entre 1963 e 1969 em Saránsk e, em seguida, materiais coletados em arquivos em São Petersburgo, Moscou, Oriol, Odessa, Vítebck, Velíki Luk, Vilno, Kustanái e Saránsk. O livro está organizado em 9 capítulos mais anexos, a saber:

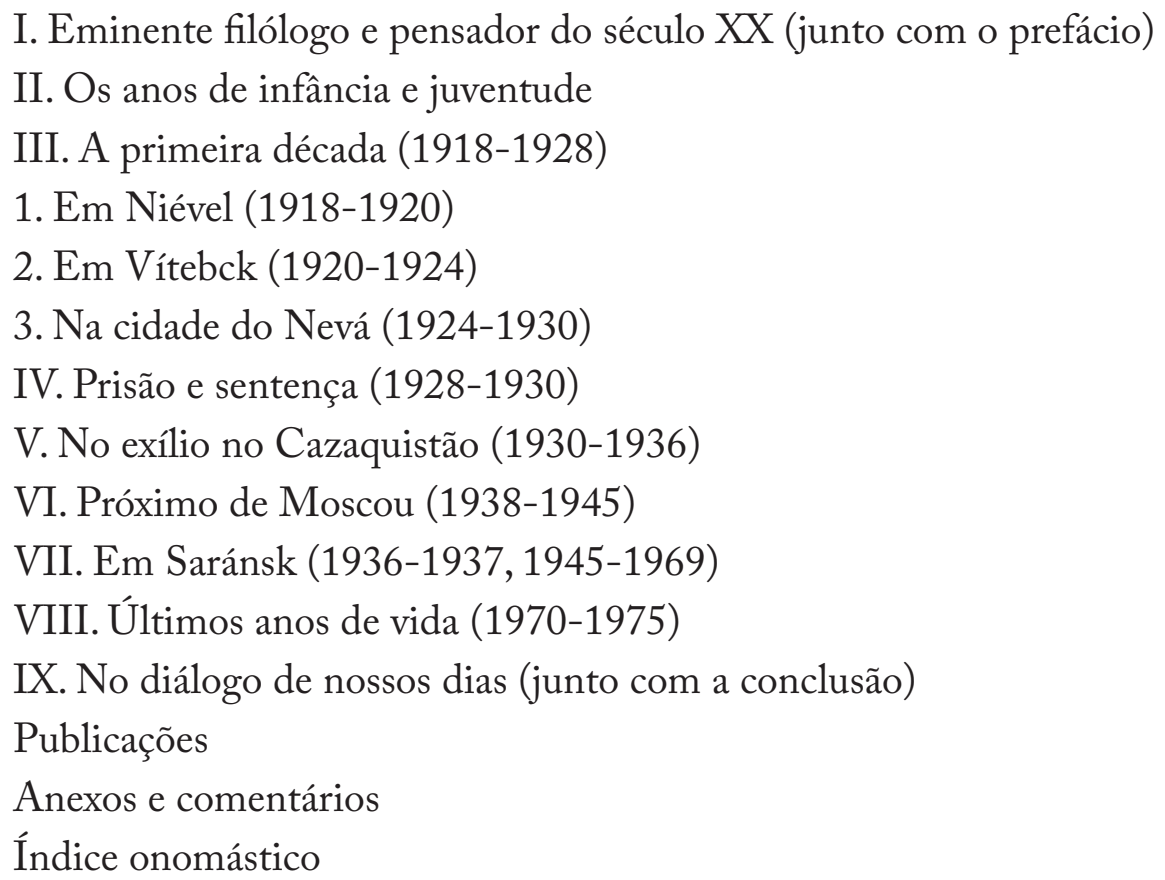

No capítulo "Eminente filólogo e pensador do século XX (junto com o prefácio)", os autores relatam diversos aspectos da vida de M. M. Bakhtin. Primeiramente, destacam sua atuação como chefe do departamento de literatura russa e estrangeira. Em seguida, Kónkin e Kónkina discutem e definem as linhas mestras da obra bakhtiniana. Para isso, começam por abordar a complexa questão do campo de atuação de Bakhtin e concluem que os principais objetos do seu trabalho foram a teoria da literatura e a linguística filosóficas.

Apesar de parecer que essa definição reduziria o campo de atuação de Bakhtin, Kónkin e Kónkina entendem que, para ele, a literatura é a essência da arte como atividade humana, que só se constitui por meio da linguagem (rietch). A esse respeito os autores citam a seguinte passagem de O problema do texto na linguística, na filologia e em outras ciências humanas de Bakhtin - "A língua, a palavra são quase tudo na vida humana" (2016 [1959-1960] p. 93) - e postulam que a palavra, entendida como linguagem verbal, é: um elemento primordial da literatura, um 
Linha D'Água (Online), São Paulo, v. 33, n. 3, p. 1-23, set.-dez. 2020

instrumento fundamental da cultura, um meio de interação dialógica e de enriquecimento mútuo das culturas dos diferentes povos, países e épocas. Juntamente com a linguagem, o diálogo é a segunda peça chave da teoria de Bakhtin, para quem viver é participar do diálogo.

$\mathrm{Na}$ sequência, é abordado o difícil problema dos textos disputados. Os biógrafos expõem várias idéias correntes na União Soviética e na Rússia: a identidade de ideias, conceitos e conclusões entre as obras; o fato de a maior parte das formulações serem de Bakhtin, sem cuja participação as obras não teriam sido lançadas; o conteúdo dos trabalhos foi discutido no Círculo em uma atmosfera carnavalizada; Bakhtin escreveu esses livros em uma "outra entonação, com uma outra voz" (“в иной ... интонации, иным голосом, 1993, p. 16). Apesar de todas as posições expostas apontarem para a autoria exclusiva ou majoritária de Bakhtin, Kónkin e Kónkina concluem essa discussão com a proposição de que Bakhtin não desejou esclarecer completamente essa questão e com a citação de S. S. Aviérintsev: "deixar o problema sem solução e não considerá-lo passível de ser solucionado”(“оставить проблему нерешенной и считать её не подлежащей решению, 1988, p.259).

A próxima questão a ser tratada - a nosso ver fundamental e ainda pouco conhecida do público brasileiro - são os precursores de Bakhtin. De modo sintético, M. M. Bakhtin formou sua visão de mundo científico-teórica sob o influxo de duas grandes tradições: européia e russa. Do lado da tradição européia, destaca-se a influência da filosofia alemã do século XVIII ao início do XX. Do lado russo, as raízes e fontes estão nos filósofos idealistas russos Vladímir Solovióv, Pável Floriénski, Georgui Fedótov, Liev Karssávin, Aleksándr Berdiáev, Ivan Ilin, e os simbolistas russos Andrei Biéli e Viatchesláv Ivánov. Nessa tradição russa está, a nosso ver, uma das chaves da compreensão da resposta bakhtiniana à tradição das ciências humanas no Ocidente. No entanto, a questão é complexa. Por um lado, na recente edição de Problemas da criação de Dostoiérski e Problemas da poética de Dostoiérski da editora Tsentr gumanitárnikh initsiatív, a prefaciadora Boniétskaia (2017a e b) aponta a influência fundamental dos filósofos idealistas religiosos russos. Por outro, Botcharóv (2017), em seu prefácio à outra edição dessas mesmas obras, não faz qualquer menção a esses autores. Professores e estudiosos da obra de Bakhtin consultados por nós em entrevistas pessoais afirmam que Bakhtin certamente conhecia esses filósofos, mas 
Linha D'Água (Online), São Paulo, v. 33, n. 3, p. 1-23, set.-dez. 2020

que eles não poderiam ter sido citados, devido ao regime soviético, e que preferem ater-se às posições de Botcharóv, amigo, editor e estudioso da obra bakhtiniana.

Esse primeiro capítulo encerra-se com o esclarecimento sobre a origem familiar de Bakhtin na intelligentsia russa pré-revolucionária, que, em razão de seus compromissos éticos com os destinos do povo russo, manteve-se unido a este no enfrentamento de todas as adversidades.

No capítulo "II. Os anos de infância e juventude" apresentam-se as origens familiares de M. M. Bakhtin, a sua formação escolar e universitária, a trajetória de Nikolai Bakhtin e o destino de seus pais e três irmãs. Mikhail Mikháilovitch Bakhtin nasceu em 4 de novembro de 1895, em Oriol, de uma família de comerciantes (купцы). Kónkin e Kónkina apontam que Holquist e Clark 1998 [1984] equivocaram-se, ao informarem que Bakhtin provinha de uma família de nobres. Os pais amavam e valorizavam a leitura de obras de literatura e de ciência. Mikhail e seu irmão Nikolai foram educados por uma governanta alemã, que lhes ensinou alemão, e ainda no ginásio apaixonaram-se pelos simbolistas russos Dmítri Merejikóvski, Viatchesláv Ivánov, Aleksándr Blok e Andrei Biéli. Os Bakhtin gostavam de ouvir compositores como Beethoven, Chopin, Mozart. A cidade de Oriol era uma cidade industrial e comercial próspera, bem como um centro cultural. Em 1905, os Bakhtin mudaram-se para Vilno (atual Vilnus) e, em 1912, Mikhail ingressou na Faculdade Novorossísk da Universidade de Odessa, no curso de história e filologia. Por volta de 1916, os Bakhtin mudam-se para Petrogrado, onde Mikhail estudou sobretudo filosofia, literatura russa e ocidental, línguas clássicas na Faculdade de História e Filologia da Universidade de Petrogrado. As informações sobre a formação universitária de Mikhail são obscuras. Os biógrafos relatam haver registros de Nikolai Bakhtin nessa universidade, mas que o nome de Mikhail não se encontra nos registros e que provavelmente ele a frequentou como ouvinte. Nos arquivos da KGB, eles encontram um questionário, no qual Bakhtin afirma que frequentou as Universidades de Odessa e Petrogrado, mas não obteve diploma. Em seus materiais autobiográficos, Bakhtin declara que finalizou sua formação univesitária em 1918.

Os biógrafos iniciam o capítulo III, "A primeira década (1918-1928)", com depoimentos de Máximo Gorki sobre a situação em Petrogrado, entre 1917 e 1918: falta de alimentos, fome e um clima de animozidade e violência contra a intelligentsia. 
Linha D'Água (Online), São Paulo, v. 33, n. 3, p. 1-23, set.-dez. 2020

Entre 1927 e 1929, a população de Petrogrado diminuiu de 2,5 milhões para 900 mil habitantes. Em razão de condições adversas extremas, os Bakhtin partiram para Niével no verão de 1918. A seguir, o capítulo é dividido em três momentos.

O primeiro, "Em Niével (1918-1920)", relata a ida de Mikhail Bakhtin e sua família para tal cidade, rica de recursos naturais, às margens do rio Niével, com gêneros alimentícios mais fartos e baratos. Em uma escola dessa cidade, Mikhail Bakhtin ensinou história, sociologia e língua russa. Em Niével, encontrou-se um grupo de jovens talentosos que formaram um círculo filosófico conhecido como "Seminário kantiano" e que funcionou até o final de 1918: Liev Vassílievitch Pumpiánski, nascido em 1891 em Vilno, estudou filologia românica e alemã e depois história da literatura russa e da Europa Ocidental na Universidade de São Petersburgo; Valentín Nikoláievitch Volóchinov, nascido em 1895 em São Petersburgo, estudou 2 anos de direito na Universidade de São Petersburgo e deixou o curso devido a dificuldades financeiras; Borís Mikháilovich Zubákin, nascido em 1894, poeta improvisador, escultor e arqueólogo; Maria Veniamínovna Iúdina, nascida em 1899 em Niével, estudou no Convervatório de Petrogrado e em 1918, para tratar uma doença nas mãos, voltou a Niével, onde trabalhou como professora em um jardim de infância e estudou intensamente filosofia; Matvéi Issáevitch Kagán, nascido em 1889 na região de Pskóvski, partiu em 1909 para estudar filosofia na Alemanha e voltou a Niével em 1918, onde tinha passado a infância e onde dirigiu o estudo da Crítica da razão pura de Emanuel Kant no "Seminário kantiano". O texto de Bakhtin "Arte e responsabilidade" foi publicado no almanaque de Niével Dién iskússtva [Dia da arte], em 1919.

No segundo momento, "Em Vítebck (1920-1924)", desaparecem informações sobre a família de Bakhtin e relata-se apenas que ele chegou à cidade no verão de 1920. Vítebsk é descrita como um centro cultural importante à época, ao qual afluíram pessoas de grande cultura e sentimentos patrióticos profundos: Marc Chagal (natural da cidade), Kazimír Maliévitch, Mstisláv Dobujínski, muitos professores e músicos da capital. V. Volóchinov organizou uma orquestra de câmara e trabalhou como vice-diretor de artes da seção governamental de educação do povo. M. Bakhtin trabalhou como professor de literatura no Instituto Pedagógico de Vítebsk e de história e filosofia da música no Conservatório dessa cidade. Kónkin e 
Linha D'Água (Online), São Paulo, v. 33, n. 3, p. 1-23, set.-dez. 2020

Kónkina escrevem que "em torno de Bakhtin formou-se um novo círculo" (p. 63) composto por V. Volóchinov, P. N. Medviédev, I. I. Sollertínski, K. V. Pumpiánski e outros intelectuais locais. Contudo, M. Kagan não participou do grupo, mas mudou-se para Oriel em 1920 para trabalhar em uma universidade recém criada. A fonte da maior parte das informações da vida de M. Bakhtin é extraída de cartas enviadas a M. Kagan, por meio das quais é possível perceber a estreita amizade entre eles. Em uma delas, datada de 20 de fevereiro de 1921, aparece pela primeira vez a menção a uma doença dos ossos que o deixou de cama por semanas e que o acompanharia por toda a vida. Em outra, sabemos que o casamento de M. Bakhtin com Elena Aleksandrovna Okolóvitch (1901-1971) ocorreu em 10 de novembro de 1921. Por essas cartas, tomamos conhecimento de que M. Bakhtin trabalha sobre "estética da criação verbal», sobre "sujeito da moral e sujeito do direito", cujos resultados os biógrafos revelam não ter chegado até nós no volume em que são relatados por Bakhtin, e sobre Dostoiévski. É em Vítebsk que Bakhtin escreveu Por uma filosofia do ato, $O$ autor e o herói na atividade estética e iniciou o trabalho sobre Dostoiévski, os três em ligação estreita.

No terceiro momento, "Na cidade do Nevá (1924-1930)", Bakhtin parte para Leningrado no verão de 1924, onde permanece até a primavera de 1930. Segundo os biógrafos, "é nesse momento que M. Bakhtin torna-se o cientista que entrou para a história da ciência nacional"' (1993, p. 98). Nesse período, M. Bakhtin trabalhou extra-oficialmente no Instituto da História da Arte, onde há um registro de que proferiu a palestra "O problema do personagem na criação literária", e como editor em Leninzdat, editora para a qual produziu dois trabalhos sobre Tolstói, que se tornaram prefácios aos volumes 11 e 13 da obra completa de L. N. Tolstói. Segundo os biógrafos, essas atividades não proviam o sustento de sua família, mas, apesar das grandes dificuldades financeiras, M. Bakhtin dedicou-se ao aprofundamento das fontes científicas que lhe eram inacessíveis antes. Para obter algum dinheiro, Bakhtin apresentava-se em bibliotecas da cidade com resenhas sobre livros lançados, o que the deu a oportuniade de ler muito do que foi produzido à época. É desses anos o

\footnotetext{
5 "вокруг М. Бахтина очень скоро складывается новый кружок"

6 "что именно в это время М. Бахтин стал темучёным, каким вошёл он в историю отечественной науки"
} 
Linha D'Água (Online), São Paulo, v. 33, n. 3, p. 1-23, set.-dez. 2020

artigo "O problema do conteúdo, do material e da forma na criação artística verbal" (Проблема содержания, материала, и формы в словесном художественном творчестве) (1924), que não foi publicado naquele momento, devido ao fechamento da revista "Rússkii sovremiénnik". Em Leningrado, novamente formou-se um círculo de intelectuais composto por V. N. Volóchinov, P. N. Medviédev, L. V. Pumpiánski, I. I. Kanáiev (biólogo), K. K. Váguinov (escritor e poeta), N. I. Kónrad (estudioso das línguas e culturas do Japão, Coreia e China), B. V.Zaliésski (engenheiro e geólogo), M. V. Iúdina (pianista), além de poetas que frequentavam o grupo esporadicamente. Os biógrafos confessam não ter informações precisas sobre o conteúdo e o caráter das reuniões do grupo, mas relatam um interesse crescente por questões religioso-filosóficas e religioso-morais em diversos círculos da cidade, inclusive no de Bakhtin, sob a influência de filósofos religiosos como V. Solovióv, V. Rózanov, N. Berdiáev, P. Florénski, S. Bulgákov, N. Lósski e P. Sorókin. Na sequência, os biógrafos voltam a defender a autoria bakhtiniana dos textos disputados com base na "lógica de seu pensamento científico" (“логика его научного мышления”, 1993, p. 115) e os comentam um a um. Os biógrafos ressaltam que, embora Volóchinov fosse uma pessoa destacada, sua formação antes do encontro com Bakhtin era, assim como a de Medviédev, em Direito e que a escolha do curso de etnolinguística na Universidade de Leningrado em 1924 já se deu sob a influência de Bakhtin, o qual o teria ajudado na universidade e em seu doutoramento no ILIAZV.

No capítulo IV, "Prisão e sentença (1928-1930)", os biógrafios baseiam-se em farta documentação (cartas, testemunhos escritos, documentos de arquivo da KGB etc.) para relatar as circunstâncias em que Mikhail Bakhtin foi preso, e depois condenado, na noite de 24 de dezembro de 1928 (quando também foram apreendidos seus manuscritos, cartas, fotografias, livros), acusado de atividade contrarrevolucionária por participação no grupo Voskressiénie (Ressurreição). O grupo Voskressiénie foi fundado por Aleksándr Aleksándrovitch Meier (1882-1939) no final de 1917 e consistia em um grupo de caráter religioso-filosófico e composto por um conjunto heterogêneo de intelectuais (entre 150 e 200 pessoas) que buscavam compatibilizar os princípios do socialismo cristão com o socialismo marxista. Segundo os biógrafos, nas reuniões do "Voskressiénie", Mikhail fez conferências sobre Dostoiévski, os simbolistas, Viatchesláv Ivánov, Kant e os neokantianos, 
Linha D'Água (Online), São Paulo, v. 33, n. 3, p. 1-23, set.-dez. 2020

Nieztche, Husserl, bem como muitos outros pensadores e escritores russos e da Europa Ocidental. No entanto, o grupo foi acusado de ser uma organização contrarrevolucionária clandestina com o propósito de derrubar o poder soviético e extinto em dezembro de 1928 com a prisão de todos os seus membros, aproximadamente 200 pessoas. Durante o processo de acusação, a osteomilite de Bakhtin piorou e ele foi internando, passando por uma cirurgia. Do hospital, ele recebeu o resultado de sua condenação: 5 anos de campo de concentração em Solovkí, o célebre campo localizado em uma ilha no norte da Rússia, onde muitos condenados encontraram a morte. Em razão da frágil condição de saúde de Bakhtin, iniciou-se uma campanha para amenizar sua pena, da qual participaram sua esposa Elena, A. V. Lunatchárski (secretário da educação do partido comunista e autor de uma longa resenha a respeito do livro Problemas da criação de Dostoiéruski), o escritor Alekséi Tolstói, Maria Iúdina e outros. Mediante uma comissão médica, cujo relatório atestou a fragilidade da saúde de Mikhail Bakhtin, a pena foi transformada em 5 anos de exílio em Kustanai, para onde Mikhail e sua esposa partiram apenas em 29 de março de 1930, quando o estado de saúde de Mikhail melhorou.

Segundo os biógrafos, o livro Problemas da criação de Dostoiérski, publicado em 1929, ocupa um lugar central nas pesquisas de Bakhtin nos anos 1920, e foi com esse trabalho que se formulou o sistema de pensamento que elevou Bakhtin ao mais alto nível das ciências humanas do século XX. Há notícias de que o livro começou a ser escrito em 1922, mas foi com o desenvolvimento dos trabalhos assinados por Medviédev ("O método formal nos estudos literários. Introdução crítica a uma poética sociológica", 1928) e por Volóchinov ("Marxismo e filosofia da linguagem. Problemas fundamentais do método sociológico na ciência na linguagem”, 1929, além de artigos) que o texto sobre Dostiévski ganhou sua versão final.

No capítulo "V, “O Exílio no Cazaquistão", (1930-1936), declara-se que não há materiais de arquivo desse período da vida dos Bakhtin e que a principal fonte das informações provém de relatos orais de Mikhail e sua esposa à época em que já estavam em Saránsk e que foram presenciados pelos próprios biógrafos. No final do capítulo, algumas informações sobre os Bakhtin são baseadas em cartas do arquivo de M. Kagán. Primeiramente, relata-se o clima inóspito de Kustanai, uma cidade com economia agrícola e com temperaturas que chegavam a 40 graus negativos no 
Linha D'Água (Online), São Paulo, v. 33, n. 3, p. 1-23, set.-dez. 2020

inverno, o que não ajudava na recuperação da saúde de Mikhail. Apesar de estar proibido de ensinar, depois de aproximadamente um ano de exílio e em razão da carência de professores qualificados, Bakhtin começou a lecionar esporadicamente em instituições de ensino. No entanto, ele conseguiu um trabalho estável de contador em uma cooperativa local em 23 de abril de 1931, onde permaneceu até outono de 1936. Bakhtin dedicou-se ao estudo da demanda de produtos industrializados pelos trabalhadores do kolkhóz (propriedade rural coletiva) e produziu um artigo ${ }^{7}$. Nessa época, "praticamente não houve contato com amigos petersburguenses e moscovitas, a não ser raras e fieis surpresas. Somente uma vez I. I. Kanáiev veio a Kustanai de Leningrado" ${ }^{8}$ Em razão da condenação política, as cartas de M. Bakhtin eram vigiadas e por isso ele não as escreveu nesse período. Em 1936, M. Bakhtin viajou a Leningrado para cuidar de sua saúde e talvez encontrar uma oportunidade na capital. Com a ajuda de Pável Medviédev, M. Bakhtin aceitou um posto no Instituto Pedagógico da Mordóvia, em Saránsk, para onde partiu em outubro de 1936, mas no final do ano letivo de 1936/1937, os Bakhtin tiveram que deixar a cidade e o trabalho'. O casal circulou por algum tempo entre Moscou, Leningrado e voltou a Saránsk no outono de 1937, mas, depois de dois ou três meses, deixou a cidade. Apesar de ter sido excluído do contato com o mundo científico, nesse período Bakhtin produziu uma de suas obras mais conhecidas, $O$ discurso no romance. Os biógrafos não fornecem informações sobre o processo de produção desse texto, mas afirmam que, depois de décadas, ele não perdeu sua relevância científicoteórica e relatam testemunhos de cientistas contemporâneos a respeito da originalidade da abordagem bakhtiniana, que repousa sobretudo na concepção do papel da palavra, do discurso no romance.

O capítulo “VI. Próximo de Moscou (1938-1945)” começa com a transcrição de um trecho de uma carta de Kagán a sua esposa, na qual relata as dificuldades e o estado físico dos Bakhtin. A osteomilite de Bakhtin piorou e ele sofreu a amputação de uma perna em 13 de fevereiro de $1938^{10}$. Apesar de estar proibido de morar

7 BAKHTIN, M. M. Ópit izutchiéniia spróssa kolkhóznikov, Soviétskaia torgóvlia, n. 3, 1934.

8 "Связей с питерскими и моковскими друзъями проактически не было, если не считать весьма редких и надёжных оказий. Только однажды из Лениграда приезжал в Кустанай их друг И. И. Канаев. (1993, р. 208)

9 Os biógrafos voltarão às causas e circuntâncias dessa partida forçada no capítulo VII.

10 Durante estágio de pesquisa em Saránsk, as professoras coordenadoras do Centro de 
Linha D'Água (Online), São Paulo, v. 33, n. 3, p. 1-23, set.-dez. 2020

em Moscou, os dirigentes do Instituto das Literaturas do Mundo Im. Górkogo (IMLI) concordaram em aceitar Bakhtin como colaborador científico, o que significava nenhuma remuneração substancial. Livre para pesquisar em bibliotecas, Mikhail continuou seu trabalho sobre a teoria do romance e produziu os textos "As formas do tempo e do cronotopo", "Da pré-história do Discurso Romanesco" e "Epos e romance (sobre a metodologia do romance)", que foram apresentados como palestras na seção de teoria da literatura e estética do IMLI, em 14 de outubro de 1940 e 24 de março de 1941. Em 1941, Mikhail conseguiu trabalho em uma escola do ensino fundamental da região de Kimrí e Ilínskoie onde ficou somente 2 meses. Em seguida, em 1942, ele foi nomeado na escola 14 e também atuou na escola n. 39 em Kmrí, onde ensinou línguas russa e alemã e literatura russa. Os biógrafos citam depoimentos de ex-alunos que relatam as dificuldades agravadas pelos tempos de Guerra: as escolas não eram aquecidas, passavam frio e fome, inclusive Bakhtin, que parecia se esquecer de tudo isso, quando ensinava ${ }^{11}$. A última parte deste capítulo é dedicada à síntese e comentários a respeito da dissertação "François Rabelais na história do realismo" (trabalho publicado nos anos 1960 com o título A obra de François Rabelais e a cultura popular na Idade Média e no Renascimento), "A formas do tempo e do cronotopo no romance”, "Da pré-história do discurso Romanesco" e "Epos e romance”. As sínteses são bem-feitas, porém não acrescentam muito para quem já conhece a obra bakhtiniana.

No próximo capítulo, “VII. Em Saránsk (1936-1937, 1945-1969)”, os biógrafos abordam todo o período de vida de Bakhtin nessa cidade. A sua nomeação para a função de professor de literatura geral no Instituto Pedagógico de Saránsk em 1936 coincidiu com o período de recrudecimento do regime stalinista. Os biógrafos relatam um clima de denúncias e intrigas no Instituto, que culmina com

Bakhtin Svetlána Dubróvskaia e Irina Kliúeva relataram a Sheila Grillo que a esposa de Bakhtin contou ter sido cogitada a possibilidade de amputar ambas as pernas, em razão das dores intensas que impediam Mikhail até de pensar, mas que depois decidiram por uma perna e mesmo assim, depois da operação, arrependeram-se de tê-la amputado!

11 É dessa época o manuscrito bakhtiniano "Vorpóssi stilístiki na urókhax rússkogo iaziká v sriédnei chkóle", traduzido para o português em BAKHTIN, M. M. Questões de estilística no ensino de língua. Trad. S. Grillo e E. V. Américo. São Paulo: Editora 34, 2013, mas não há menção a esse texto na biografia. 
Linha D'Água (Online), São Paulo, v. 33, n. 3, p. 1-23, set.-dez. 2020

a condenação de um professor a 5 anos de campo de concentração por atividade contrarrevolucionária. $\mathrm{O}$ diretor e o vice-diretor do instituto foram demitidos e Bakhtin pediu demissão alegando problemas de saúde ${ }^{12}$. Neste ponto, retoma-se brevemente o período narrado no capítulo anterior em que Mikhail viveu próximo a Moscou e trabalhou em escolas do ensino fundamental. Em seguida, com base em documentos oficiais, os biógrafos relatam a nomeação de Bakhtin pelo Comissariado da Educação, como professor de literatura geral no Instituto Estatal Pedagógico de Saránsk, em 18 de agosto de 1945. De 1945 a 1957²3, M. Bakhtin deu aulas de introdução à teoria literária, história da literatura da Europa Ocidental, começando pelas literaturas Grega e Romana antigas, e metodologia de ensino de literatura no ensino fundamental. Depoimentos de estudantes atestam o empenho de Bakhtin e a admiração dos alunos por seu conhecimento, animação e gentileza. Bakhtin defendeu sua tese "François Rabelais na história do realismo"14 em 15 de novembro de 1946 no Instituto das Literaturas do Mundo Im. Górkogo (IMLI), mas só recebeu o título de doutor em 1952, em razão de problemas na Comissão Superior de Diplomas em decorrência da votação do título de "livre-docente" (dóktor nayk). Contudo, logo após a defesa da tese (15 de novembro de 1946), Bakhtin foi nomeado chefe do departamento de literatura geral, cargo que ocupou até 1957. Com base em atas de reuniões do departamento de literatura geral e russa, os biógrafos expõem a metodologia de ensino que Bakhtin implantou: estímulo à formação do pensamento crítico, separação dos conhecimentos fundamentais daqueles discutíveis, necessidade de conhecer e mostrar as fontes dos textos literários, exposição da posição pessoal do professor sobre os temas abordados, compreensão da literatura como arte e comparação com outras modalidades artísticas (pintura, música etc.), aliança entre teoria e conhecimento histórico.

12 Embora os biógrafos não forneçam mais detalhes sobre o assunto, Laptun (1991) escreve, baseado em textos de jornais de Saránsk, sobre uma campanha contra a nomeação de Bakhtin em razão de ele ter sido condenado por atividade contrarrevolucionária.

13 Estas datas e informações aparecem na página 258. Contudo, nas páginas 269 e 382, sabemos que Bakhtin aposentou-se em 1961 e que ele dirigiv o departamento de literatura russa e geral até 1961.

14 No artigo de Pankóv (1993), com base em farta documentação, relata-se que o plano inicial de Bakhtin para esse trabalho, finalizado em 1930, era a publicação de um livro para um público muito mais amplo de leitores do que a esfera acadêmica, mas isso acabou não acontecendo. 
Apesar da grande quantidade de aulas e do trabalho de chefia, Bakhtin relata seus trabalhos de pesquisa em relatórios preservados em arquivos estatais de Saránsk. Os biógrafos relacionam os seguintes textos produzidos por Bakhtin durante seu período de atuação na universidade: na segunda metade dos anos 1940, 1) "Stilístika romana"[A estilística do romance], 2) "Rablié i Gógol” [Rabelais e Gógol], 3) "Burjuáznie kontsiéptsii épokhi Vozrojdiénia"[Concepções burguesas da época do Renascimento]; na primeira metade dos anos 1950, 4) "Probliéma rietchevíkh jánrov"[O problema dos gêneros do discurso], 5) “Slóvo kak óbraz” [A palavra como imagem], 6) "Istótchniki kontsiépsii A. N. Vesselóvskogo" [Fontes das concepções de Vesselóvski], 7) “Krítika kontsiépsiii A. N. Vesselóvskogo” [Crítica das concepções de Vesselóvski]; na segunda metade dos anos 1950, 8) "Probliémi estetítcheskikh kategórii”[Problemas das categorias estéticas], 9) “Probliéma centimentalízma vo frantsúzoi literatúre" [O problema do sentimentalismo na literatura francesa], 10) "Probliéma tiéksta v lingvístike, filológuii i druguíkh gumanitárnikh naúkax. Ópit filossófskogo análisa” [O problema do texto na linguística, filolosofia e em outras ciências humanas. Ensaio de análise filosófica], 11) "K pererabótke knígui o Dostoiévskom” [Reformulação sobre o livro de Dostoiévski]. Entre os onze textos listados, apenas os números 2, 4, 10 e 11 foram efetivamente publicados e, mesmo assim, após a morte de Mikhail Bakhtin.

A aposentadoria de Bakhtin acontece em 1 de agosto de 1961, aos 66 anos, e, segundo os biógrafos, sua situação financeira era confortável. Ainda em Saránsk e aposentado, Bakhtin produziu e/ou publicou os seguintes textos: "Probliémi poétiki Dostoiévskogo" [Problemas da poética de Dostoiévski, 1963], “Tvórtchestvo Fransuá Rablié i naródnaia cultúra srednevekóviia i Renessansa" [A obra de François Rabelais e a cultura popular na Idade Média e no Renascimento, 1965], e "Iz predstórii románnogo slóva" [Da pré-história da palavra romanesca", 1967]. Assim como os textos anteriormente mencionados, estes são resumidos pelos biógrafos e, no caso de Problemas da poética de Dostoiérski, são relatadas as resenhas que saíram após sua publicação, algumas elogiosas e outras nem tanto. Segundo os biógrafos, a dissertação sobre Rabelais tinha sido entregue ao Instituto das Literaturas do Mundo Im. Górkogo em 1940, porém, com o início da Segunda Guerra Mundial em junho de 1941, o trabalho ficou parado e a defesa só aconteceu em 1946. Em razão da tradução para 
Linha D'Água (Online), São Paulo, v. 33, n. 3, p. 1-23, set.-dez. 2020

o russo de Gargantua e Pantagruel no início dos anos 1960, o teórico da literatura V. Vinográdov, o escritor K. Fiédin e o tradutor de Rabelais, N. Liubímov, dirigiram-se à editora "Khudójestvennaia literatura" [Literatura artística] com a recomendação da publicação rápida do livro de Bakhtin, o que, após a revisão deste, aconteceu em 1965. Desta vez, as críticas tanto de teóricos da literatura quanto de historiadores russos foram bem mais acolhedoras e elogiosas. Em 1967, Bakhtin recebeu a notícia de Kanáiev, de que a justiça reconhecia que sua condenação por atividade contrarrevolucionária para derrubar o governo soviético foi equivocada e que, na verdade, o grupo "Voskressiénie" consistia em reuniões de intelectuais em seus apartamentos para discutir questões religiosas e filosóficas. Em 1969, em razão de problemas de saúde do casal e graças à ajuda de amigos e oficiais da KGB, Bakhtin e sua esposa partem para serem tratados em um hospital de Moscou.

O capítulo VII, “Os últimos anos de vida (1970-1975)”, começa com os Bakhtin na clínica Kremlióvskaia em Kúntsevo, Moscou, onde foram tratados por 7 meses. Em maio de 1970, o casal foi instalado em uma casa para idosos na cidade de Klímovsk, a aproximadamente $50 \mathrm{~km}$ ao sul de Moscou. Os biógrafos relatam que, no início de 1971, Bakhtin já não suportava o lugar, em razão do isolamento do meio universitário com o qual estava habituado e da convivência com muitas pessoas no fim da vida e muitas delas já fora de si. Em 14 de dezembro de 1971, Elena Aleksandróvna faleceu, o que deixou Mikhail Bakhtin bastante abalado de saúde e de ânimo. Em 1972, Baktin, enquanto membro da União dos Escritores da Rússia, para a qual entrou em 24 de novembro de 1970, foi transferido para a Casa de Escritores em Perediélkino, um povoado próximo a Moscou, onde permaneceu por 8 meses até setembro de 1972. Dali, mudou-se para um apartamento em Moscou pertencente à União de Escritores, para onde transferiu seus móveis e livros do apartamento de Saránsk. A saúde de M. Bakhtin começou a piorar muito no fim de 1974 e ele faleceu em 6 de março de 1975. A notícia de sua morte foi divulgada em muitos jornais e revistas literários. Nesses últimos anos de vida, Bakhtin continuou a trabalhar e produziu, entre outros, os textos: "Otviét na voprós redáktsii “Nóvogo míra” [Resposta a uma questão da revista 'Nóvi Mir'], “Iz zápissei 1970-1971 godóv” [Apontamentos de 1970-1971], “K metodológuii gumanitárnikh naúk" [Por uma metodologia das ciências humanas] e "Zamiétki" [Notas]. 
Linha D'Água (Online), São Paulo, v. 33, n. 3, p. 1-23, set.-dez. 2020

Assim como fizeram em outros capítulos, os biógrafos sintetizam as linhas mestras desses textos e os colocam em relação com obras dos anos 1920, considerando que nelas Bakhtin realizou um balanço de sua produção intelectual.

Por fim, no capítulo IX, "No diálogo de nossos dias", os biógrafos analisam uma pequena parte da bibliografia russa dedicada ao estudo da herança científica de Bakhtin. A síntese dos biógrafos é que o sistema de pensamento bakhtiniano formou-se nos anos 1920 em diálogo estreito com as tendências mais importantes do pensamento russo e da Europa Ocidental na virada dos séculos XIX e XX, mas, até aquele momento, ainda não tinha sido feito um levantamento sistemático dessas influências. Os comentadores avaliam que a contribuição bakhtiniana continuava atual e em diálogo com as questões daquele momento (início dos anos 1990). Segundo alguns autores, não se deve falar de evolução do pensamento bakhtiniano ao longo das décadas, mas de uma revelação gradual de um único núcleo semântico. Interpreta-se ainda o conceito bakhtiniano de diálogo de culturas e do diálogo como uma forma de oposição ideológica ao stalinismo e ao culto do líder. A fortuna crítica avalia ainda vários outros aspectos da obra bakhtiniana que citamos apenas como uma referência do que foi enfatizado: a filosofia da literatura, a relação eu/outro, o papel protagonista do autor e seu excedente de visão, o caráter coletivo da criação, a metalinguística.

Nos anexos, encontramos dois pequenos artigos jornalísticos de Bakhtin: o primeiro, "Niékotorie zametchániia" [Algumas recomendações], é um texto publicado no jornal da universidade de Mordóvia, em 18 de novembro de 1958, no qual Bakhtin traz recomendações a estudantes universitários de como ler textos científicos; o segundo "Maríia Tiúdor" [Maria Túdor], é uma resenha sobre a encenação da peça homônima de Victor Hugo no jornal Soviétskaia Mordóviia, em 12 de dezembro de 1954. Os biógrafos informam que Bakhtin produziu tais textos com certa frequência e que, até aquele momento, ainda esse material não havia sido reunido. Há também uma relação de sete livros publicados por Bakhtin na União Soviética, além de O freudismo e Marxismo e filosofia da Linguagem, de Volóchinov, e $O$ método formal nos estudos literários, de Medviédev, que, segundo o título dos biógrafos à relação, foram escritos com a participação de M. Bakhtin.

$* * * * * *$ 
Neste dossiê da revista Linha D'água, intitulado "90 Anos de Problemas da criação de Dostoiéruski (1929-2019)", os dez artigos dialogam com as obras de Bakhtin e as do Círculo. A reunião deles se originou da seleção de trabalhos apresentados no "Colóquio Internacional 90 anos de Problemas da obra de Dostoiérski 1929-2019)", ocorrido na Universidade de São Paulo (USP) entre os dias 26 e 28 de novembro de 2019, promovido pelo Grupo de pesquisa Diálogo da Faculdade de Filosofia, Letras e Ciências Humanas (FFLCH) da USP, com apoio financeiro da FAPESP e da universidade onde se realizou.

O primeiro deles, intitulado "Crítica responsiva a diálogos polêmicos com o conceito de dialogismo de Bakhtin”, escrito por Marco Antonio Villarta-Neder e Fábio Luiz de Castro Dias, se concentra em uma discussão de cunho teórico a respeito da análise das obras de Bakhtin, tendo como eixo o conceito de dialogismo, conforme já apontado em seu títutlo. Trata-se, segundo os autores, de uma crítica responsiva a diálogos polêmicos de Caryl Emerson, autora estadunidense, com a epistemologia bakhtiniana. A metodologia se assenta no princípio do correlacionamento, o qual instaura uma intersecção dialógica entre as obras das quais se utilizam para sua análise, como enunciados responsivos. Villarta-Neder e Dias destacam, por meio do diálogo tenso na corrente da comunicação discursiva, a "presença constitutiva e reguladora de um 'nós' pressuposto" nas obras bakhtinianas, sublinhando a importância de que um olhar que se propõe dialético dialógico se constitua em uma distância crítica e necessária aos que intencionam responsavelmente "ver e compreender" o outro.

Inti Anny Queiroz, com seu artigo "Arquitetônica, relações dialógicas e metalinguística: a base do pensamento bakhtiniano", retoma a produção de Bakhtin assinalando, inicialmente, o caráter filosófico da arquitetônica, elaborada como conceito "sistematizador", logo em seus primeiros escritos. Adentrando nos aspectos éticos e estéticos, que o autor aborda ao focalizar a linguagem, em diálogo com a criação literária, Queiroz ressalta o olhar de Bakhtin para as relações dialógicas, para a responsividade constitutiva dos enunciados que percorrem suas obras. Por esse viés, a autora vai demarcando em sua análise o entendimento de que a relação eu-outro, assumida como fundante, se mostra no decorrer da escrita de um Bakhtin mais maduro, construindo seus textos junto à influência dos pensadores do 
Linha D'Água (Online), São Paulo, v. 33, n. 3, p. 1-23, set.-dez. 2020

Círculo, como Medviédev e Volóchinov. A esfera ideológica, tomada como constitutiva dos enunciados, marca o caráter sociológico dos seus trabalhos. Finalmente, Queiroz sublinha a criação da disciplina Metalinguística proposta por Bakhtin como forma de abarcar, nas análises dos enunciados concretos, seu caráter extralinguístico, construído na relação dialógica do sujeito com o mundo da cultura em que está inserido e em um permanente movimento de interação com ele.

O terceiro texto, "Estilo e estilística em Bakhtin e Volóchinov: perspectiva em diálogo", assinado por Sueli Pinheiro da Silva, toma como ponto de partida de sua reflexão uma breve retomada dos precursores da estilística no Brasil, demarcando também o momento histórico em que os autores do Círculo chegaram à realidade acadêmica brasileira, o que impactou as diferentes linhas de pesquisa da linguística e da literatura, principalmente. Em seguida, se volta ao seu objetivo principal que é o de percorrer os estudos de estilo nos trabalhos de Bakhtin e Volóchinov. A autora faz um mapeamento dos conceitos de estilo nas obras desses dois autores, optando por um percurso de análise que acompanha cronologicamente suas publicações de 1920 a 1960. Segundo Silva, Bakhtin e Volóchinov, na construção do conceito de estilo, apresentam acentos autorais peculiares ao mesmo tempo que se reconhece um elevado grau de complementaridade entre o pensamento desses autores, em que suas concepções caminham na direção de uma continuidade na qual uma obra completa e elucida a outra.

No artigo seguinte, intitulado "A tridimensionalidade verbivocovisual da linguagem bakhtiniana", Luciane de Paula e José Antonio Rodrigues Luciano, ancorados na concepção de linguagem desenvolvida por Bakhtin, Medviédev e Volóchinov, optam por aprofundar a questão de sua tridimensionalidade (verbal, visual e sonora) apontada em seus escritos. Fundamentam, a partir dessa concepção ampla apresentada por esses autores do Círculo, o conceito de linguagem verbivocovisual e assinalam sua potencialidade expressiva. Para tal, tomam para análise diversos enunciados multimodais, como pinturas de artistas renomados, filmes, curtas-metragens, memes, evidenciando a sua constituição verbivocovisual.

O quinto texto deste dossiê, de autoria de Juciane dos Santos Cavalheiro, intitula-se "Encontro no 'subsolo': Dostoiévski, Kafka e Bakhtin". A autora problematiza duas narrativas, Memórias do subsolo de Dostoiévski e $A$ construção de Kafka, a 
Linha D'Água (Online), São Paulo, v. 33, n. 3, p. 1-23, set.-dez. 2020

partir de ideias e conceitos apresentados na obra Problemas da Poética de Dostoiérski, de Bakhtin. Em ambas as novelas, Juciane acompanha como é incorporada a palavra do outro, tendo em vista que esse outro se expressa e se configura de diferentes formas nas relações dialógicas de diversas naturezas presentes nas obras analisadas.

$\mathrm{Na}$ sequência, o artigo "O conceito de grande tempo e interpretação de discursos”, de Cláudio Primo Delanoy, aproxima-se dos conceitos bakhtinianos por meio da problematização de enunciados distintos: um deles produzido em redes sociais e com muitas repercussões, em que emite apreciações do conto Branca de Neve; e outro do poema "É ela! É ela! É ela! É ela!" de Álvares de Azevedo, que também apresenta uma interpretação do mesmo conto. $\mathrm{O}$ conceito de grande tempo media as análises no que se refere à interpretação de discursos, tornando visível a ação do grande tempo, assim como o de dialogismo, valoração, compreensão responsiva ativa, com a preocupação na construção de sentidos de um enunciado.

O sétimo artigo, intitulado "Uma análise dialógica de $O$ crocodilo, de Dostoiévski, um conto na fronteira da arte e da vida", de Francisco de Freitas Leite, se volta a uma análise do conto $O$ crocodilo de Dostoiévski, como o próprio título já indica. Fundamenta-se nos conceitos de diálogo/relações dialógicas, de sátira menipeia e de final aberto, nas concepções de autor e herói, nas noções de projeto discursivo e construção de sentido e também nas concepções de atividade estética e de atividade ética. Leite torna ainda mais visível o valor artístico da obra em questão por meio do exercício analítico de uma leitura responsiva do conto, no cotejo com outras narrativas de Dostoiévski, e ao considerar seus elementos constituidores na região fronteiriça entre a vida e a arte.

No texto "Dizer-se professora/professor pela escrita: autoria e dialogia nos relatórios de estágio”, de Ana Lúcia Guedes-Pinto, os conceitos bakhtinianos de dialogia e autoria balizam a análise dos enunciados dos estudantes-estagiários de um curso de Pedagogia. Tomando para problematização os relatórios de estágio, gênero eminentemente secundário, produzidos na esfera universitária, a autora mergulha nessas produções a fim de compreender as muitas vozes discursivas que os compõem. Para tal objetivo, aporta-se principalmente na obra Problemas da poética de Dostoiérski e sinaliza a multiplicidade de vozes com as quais os textos 
analisados dialogam, tornando visível a construção de um discurso autoral, com marcas enunciativas que denotam percursos singulares de formação docente.

O nono artigo deste dossiê, de autoria de Arlete Machado Fernandes Higashi, intitulado "O destinatário-visitante presumido nas exposições de divulgação científica do Catavento Cultural”, se detém na questão da orientação discursiva ao auditório social constituinte dos enunciados verbo-visuais veiculados em exposições de divulgação científica de uma instituição cultural. Considerando as produções do Círculo bakhtiniano, a autora problematiza em que medida e como os enunciados expositivos do Catavento Cultural, sediado em São Paulo, são marcados pela presunção de um destinatário real ou hipotético. Higashi seleciona para sua análise o conteúdo temático, a construção composicional e o estilo presentes na produção discursiva da instituição, dirigida ao destinatário-visitante, reportando-se a determinados painéis expostos ao público. Ao ancorar-se no entendimento de que o enunciado se constitui na relação com o outro, a autora pontua as muitas marcas da imagem do destinatário-visitante no movimento discursivo materializado nos painéis de suas exposições.

O último artigo, de autoria de Mayra Pinto e Sandino Coelho, "Peleja histórica de Inácio de Catingueira e Romano Caluête: uma análise dialógica do repente brasileiro", se debruça sobre as diferentes vozes discursivas da poesia de repente de uma certa região da Paraíba, procurando, pelo viés da dialogia bakhtiniana, tratar da valoração social marcada nos enunciados dos diferentes interlocutores da cantoria - um escravizador e um escravizado no sertão nordestino. No caso específico desta cantoria, depara-se com uma peleja histórica, desenvolvida em sextilha, estrofe em seis versos. A poesia oral se dá de forma que o tema da diferença entre negros e brancos venha à tona, notando-se divergência entre os desfechos já registrados para tal peleja. Pinto e Coelho ainda sublinham em suas análises as acentuações valorativas diferentes para a disputa narrada no repente, que são dependentes de quem a registrou e expoem a importância tanto do contexto histórico social quanto da posição social daquele que assume a enunciação da cantoria.

A resenha da obra Linguagem e conhecimento (Bakhtin, Volóchinov, Medviédev), organizado por Beth Brait, Maria Helena Pistori e Pedro Farias Francelino encerra esse número, redigido por Vanessa Fonseca Barbosa. Esse texto retoma 
Linha D'Água (Online), São Paulo, v. 33, n. 3, p. 1-23, set.-dez. 2020

aspectos relevantes como os pressupostos do método sociológico e da metalinguística orientadores dos textos do compêndio. Também chama atenção para seu ineditismo uma vez que os autores puderam se munir do acesso direto da tradução da língua russa para o português.

Esse dossiê, portanto, pretende fornecer mais elementos para aqueles interessados em se aprofundar nas contribuições dos conceitos, da metodologia e das pesquisas produzidos por integrantes do Círculo de Bakhtin.

Ao encerrarmos este editorial, fazemos um balanço referente à publicação de 10 textos de 15 autores, representando 9 diferentes instituições brasileiras. Convidamos todos os leitores a acessar os artigos e resenha, marcados pelos relevantes resultados de pesquisa.

Tivemos uma quantidade de submissões, e mantivemos a seleção de textos porque pudemos contar com competentes pareceristas do Conselho editorial e muitos professores ad hoc. Também contamos com um corpo de revisores de língua portuguesa de excelência, o que garante a alta qualidade de Linha d'Água. Conta também com o trabalho de revisão de tradução, realizado pela professora Roseli Serra, da Universidade Católica de Pernambuco.

Neste ano de 2020, atravessamos uma fase difícil dos investimentos nas instituições de ensino superior com o congelamento de muitas verbas. Mesmo assim, Linha d'Água recebeu o auxílio do Programa de Apoio às Publicações Científicas Periódicas da Universidade de São Paulo, por meio da Agência USP de Gestão da Informação Acadêmica (Aguia), a quem agradecemos, mais uma vez, pelo inestimável e constante apoio e reconhecimento. Essas medidas têm permitido a manutenção da indexação de Linha d'Água na Web of Science, base de dados de citações científicas do Institute for Scientific Information, mantida pela Clarivate Analytics, nas áreas de Ciências Sociais, Artes e Humanidades.

Com este número, Linha d'Água torna-se, assim, um espaço aberto a publicações ligadas aos estudos de língua portuguesa, aos estudos linguístico-discursivos e sua relação com o ensino, mantendo um diálogo constante com as pesquisas desenvolvidas no Brasil e no exterior. 
Linha D'Água (Online), São Paulo, v. 33, n. 3, p. 1-23, set.-dez. 2020

\section{Referências}

AVIÉRINTSÉV, S. S. Михаил Бахтин. Ретроспектива и песректива. [Mikhail Bakhtin: retrospectiva e perspectiva]. Дружба народов, n. 3,1988.

BAKHTIN, M. М. Опыт изучения спроса колхозникоз [Ensaio de estudo da demanda pelos trabalhadores do kolkhoz], Советская торговлия, n. 3,1934.

BAKHTIN, M. М. Эстетика словесного творчества [Estética da criação verbal]. Moscou: Iskússtvo, 1979.

BAKHTIN, M. М. М. М. Бахтин. Собрание сочинений [M. M. Bakbtin. Obras reunidas]. vol. 1. Moscou: Rússkie slovarí/ Izikí slaviánskoi kultúri, 2003.

BAKHTIN, M.M. Questões de literatura e estética. A teoria do romance. Trad. A. F. Bernadini et. al. 3 ed. São Paulo: UNESP, 1993.

BAKHTIN, M. M. O freudismo: um esboço crítico. Trad. P. Bezerra. São Paulo: Perspetiva, 2001.

BAKHTIN, M. M. Estética da criação verbal. Trad. P. Bezerra. São Paulo: Martins Fontes, 2003.

BAKHTIN, M. M. Teoria do romance I. A estilística. Trad. P. Bezerra. São Paulo: Ed. 34, 2015.

BAKHTIN, M. M. Teoria do romance II. As formas do tempo e do cronotopo. Trad. P. Bezerra. São Paulo: Ed. 34, 2018.

BAKHTIN, M. M. Da pré-história do discurso Romanesco. In: - Questôes de literature e estética. A teoria do romance. Trad. A. F. Bernardini et al. São Paulo: UNESP, 1993. p. 363-396

BAKHTIN, M.M. Epos e romance (Sobre a metodologia do estudo do romance).In: BAKHTIN, M. M. Questôes de literature e estética. A teoria do romance. Trad. A. F. Bernardini et al. São Paulo: UNESP, 1993. p. 397-428.

BAKHTIN, M. M. Questóes de estilística no ensino de lingua. Trad. S. Grillo e E. V. Américo. São Paulo: Ed. 34, 2013. 
Linha D'Água (Online), São Paulo, v. 33, n. 3, p. 1-23, set.-dez. 2020

BAKHTIN, M. M. O texto na linguística, na filologia e em outras ciências humanas. In: BAKHTIN, M. M. Os gêneros do Discurso. Trad. P. Bezerra. São Paulo: Ed. 34, 2016 [1959-1960], p. $71-107$.

BAKHTIN, M. М. Избранное том I. Автор и герой в эстетическом собътии [Selę̧а̃о vol. I. $O$ autor e o personagem no acontecimento estético]. Moscou-São Petersburgo: Tsentr gumanitárnikh initsiatív, 2017a.

BAKHTIN, M. М. Избранное том II. Поэтика Достоевского [Seleção vol. II . A poética de Dostoiérski]. Moscou-São Petersburgo: Центр гуманитарних инициатив, 2017b. p. 5-12.

BAKHTIN, M. М. Проблемь поэтика Достоевского [Problemas da poética de Dostoiérski]. Moscou: Ed. “Э”, 2017.

BONIÉTSKAIA, N. Жизнь и философская идея Михаила Бахтина [Vida e ideia filosófica de Mikhail Bakhtin]. In: BAKHTIN, M. М. Избранное том I. Автор и герой в эстетическом coбbmuu [Seleção vol. I. O autor e o personagem no acontecimento estético]. Moscou-São Petersburgo: Центр гуманитарних инициатив, 2017а. p. 5-41.

BONIÉTSKAIA, N. Тема Достоевского в трудах М. М. Бахтина [O tema de Dostoiévski nos trabalhos de M. M. Bakhtin] . In: BAKHTIN, M.M. Избранное том II. Поэтика Достоевского [Selę̧ão vol. II. A poética de Dostoiévski]. Moscou-São Petersburgo: Tsentr gumanitárnikh initsiatív, 2017b. p. 5-12.

BOTCHARÓV, S. G.; GOGOTICHVÍLI, L. A.; PANKÓV, I. L.; POPOVA, I. L. M. M. Бахтин. Собрание Сочинений т. 5. Работы 1940-х - начала 1960-х годов [M. М. Ваkbtin. Obras reunidas vol. 5. Trabalhos dos anos 1940 - início dos anos 1960]. Москва: Русские Словари, 1997.

BOTCHARÓV, S. Предсловые. Коментарии. Проблемы поэтики Достовского.[Prefácio. Comentários. Problemas da Poética de Dostoiévski]. In: BAKHTIN, M. М. Проблемы поэтики Достовского [Problemas da poética de Dostoiérski]. Moccou: Ed. “Э”, 2017. p. 7-8, 594-638.

CLARK, K.; HOLQUIST, M. Mikhail Bakbtin. Trad. J. Guinsburg. São Paulo: Perspectiva, 1998 [1984].

DOSTOIÉVSKI, F. Memórias do subsolo. Trad. B. Schnaiderman. São Paulo: Ed. 34, 2000. 
Linha D'Água (Online), São Paulo, v. 33, n. 3, p. 1-23, set.-dez. 2020

GRILLO, S. V. C. O retrato de Mikhail Bakhtin em sua mais recente biografia russa (2017). In: BRAIT, B.; PISTORI, M.H.C.; FRANCELINO, P.F. Linguagem e conhecimento (Bakhtin, Volóchinov, Medviédev). Campinas: Pontes, 2019. p. 15-43.

JIZN ISSKÚSTVA [Vida da arte], n. 33, p. 4, de 22 a 28 de agosto de 1922.

KÓNKIN, S. S.; KÓNKINA, L. S. Михаил Бахтин: страницы жизни и творчетва [Mikhail Bakbtin: páginas da vida e da obra]. Saránsk: Саранск Мордовское Издательство, 1993.

KOROVACHKO, A. V. Mikhail Bakbtin. Moscou: Молодая Гвардия, 2017.

LAPTUN, V. I. M. M. Bakhtin v Saránske (1936-1937), Literatúrnii kbudójestvenii sbórnik, Saránsk, p. 291-302, 1991.

MEDVIÉDEV, P.N. O método formal nos estudos literários. Introdução crítica a uma poética sociológica. Trad. S. C. Grillo e E. V. Américo. São Paulo: Contexto, 2012.

M. M. BAKHTIN: Beciédi c V.D. Duvákinim [M.M. Bakhtin Conversas com V.D. Duvákin]. Moscou: Soglácie, 2002.

PANKÓV, H. А. От хода этого дела зависит всё дальнейшее [Do andamento desse assunto depende todo o restante], Dialóg, Karnavál, kbronotóp, n. 2-3, p. 29-54, 1993.

VOLOCHINOV, V. (Círculo de Bakhtin) A palavra na vida e a palavra na poesia: ensaios, artigos, resenhas e poemas. Trad. S. Grillo e E. V. Américo. São Paulo: Editora 34, 2019.

VOLOCHINOV, V. N. Marxismo e fllosofia da linguagem. Problemas fundamentais do método sociológico na ciência da linguagem. Trad. S. Grillo e E. V. Américo. 2 ed. São Paulo: Ed. 34, 2018.

São Paulo, novembro de 2020. 